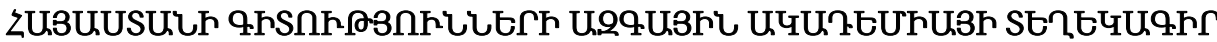 ИЗВЕСТИЯ НАЦИОНАЛЬНОЙ АКАДЕМИИ НАУК АРМЕНИИ
}

\author{
Utipuminluu \\ 72, №4, 2019 \\ Механика \\ УДК 539.3 \\ Doi- http://doi.org/10.33018/72.4.3

\section{ON AXIAL SYMMETRIC STRESS STATE OF UNIFORMLY LAYERED SPACE WITH SYSTEM OF PERIODICAL INNER DISK-SHAPED CRACKS} \\ HakobyanV.N., Dashtoyan L.L., Murashkin Ye.V.
}

Keywords: discontinuous solutions, periodic system of cracks, axial symmetric stress state.

Акопян В.Н., Даштоян Л.Л., Мурашкин Е.В.

Осесимметричное напряжённое состояние равномерно слоистого пространства, содержащей периодическую систему внутренних дискообразных трещин

Ключевые слова: разрывные решения, периодическая система трещин, осесимметричное напряжённое состояние.

В статье рассматривается осесимметричное напряжённое состояние кусочно-однородного, равномерно слоистого пространства, образованного чередующимся соединением двух неоднородных слоев одинаковой толщины, которые содержат периодические системы круглых дискообразных параллельных трещин в срединных плоскостях. Получена система определяющих уравнений задачи в виде системы интегральных уравнений типа Фредгольма, решение которой построено методом механических квадратур. Проведён численный анализ и выявлены закономерности изменения коэффициентов интенсивности разрушающих напряжений и раскрытия трещин в зависимости от физико-механических и геометрических характеристик задачи.

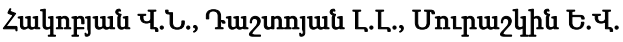

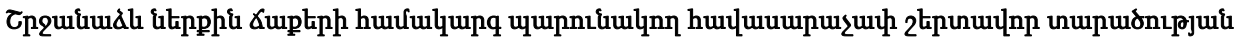

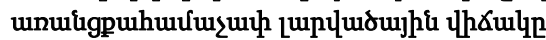

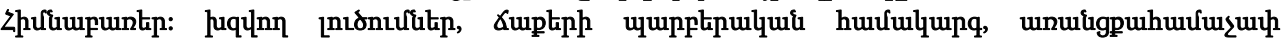

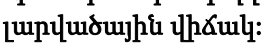

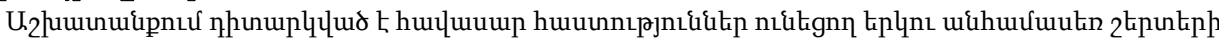

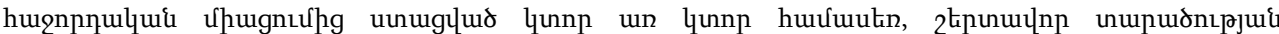

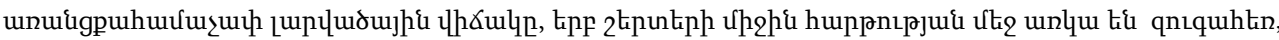

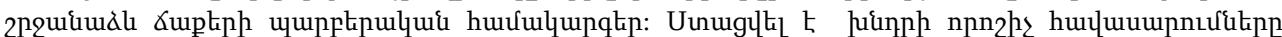

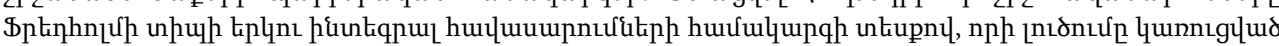

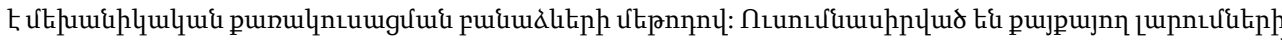

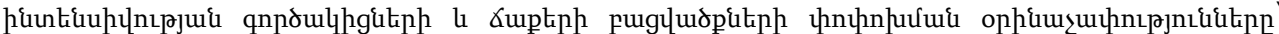

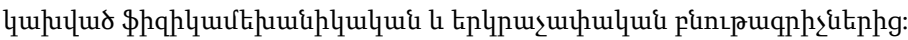

This paper considers the axisymmetric stress state of piecewise homogeneous, uniformly layered space formed by alternate junction of two heterogeneous layers with same thickness, which contains the periodical systems of circle disk-shaped parallel cracks in median plane. The governing system of integral equations for problem is obtained using the Hankel integral transformation. Using rotation operators the governing system of equations is reduced to the system of Fredholm integral equation of second kind. The system is solved by the method of mechanical quadratures. The numerical analysis is carried out and the regulations for changing of intensity factors of fracture stresses and opening of crack depending on physical and mechanical and geometrical characteristics of problem are revealed.

\section{Introduction}

Few research studies are dedicated to the analysis of the axisymmetric stress state of an elastic piecewise-homogeneous, uniformly layered space of two heterogeneous layers with 
interphase disc-shaped defects. Among them, the work [1], where the discontinuous solutions of the equations of the axisymmetric theory of elasticity are constructed for a piecewise homogeneous, uniformly layered space obtained by alternately junction of two heterogeneous layers of the same thickness, which contain a periodic system of circular discshaped parallel interphase defects is noteworthy. The solutions of two certain problems when the defect is an absolutely rigid disk-shaped inclusion and when the defect is a disk-shaped crack are obtained. Also, a complete review of the papers directly related to this article is presented here. We also cite papers [2-4], where many of the main results on axisymmetric contact and mixed boundary value problems of the theory of elasticity are demonstrated. As regards the axial symmetric stress state of a piecewise-homogeneous, layered space with a periodic system of circular disk-shaped parallel internal defects, which is interesting and relevant both from scientific and practical points of view, there are no available studies conducted to our best knowledge.

\section{The statement of problem and discontinuous solutions}

In a cylindrical coordinate system $\operatorname{Or} \varphi \mathrm{z}$, we consider the axisymmetric stress state of a piecewise-homogeneous elastic space, obtained by alternately sequenced junction of two heterogeneous layers of thickness $2 h$ with Lame coefficients $\lambda_{1}, \mu_{1}$ and $\lambda_{2}, \mu_{2}$, respectively, when on the median planes of heterogeneous layers $Z=(2 n+1) h(n \in Z)$ the space is relaxed by two systems of periodic circular disk-shaped, parallel cracks with radii $a_{j}(j=1,2)$. We assume that the space is deformed under the influence of the same axisymmetric normal loads $P_{j}(r)(j=1,2)$ acting respectively on the banks of cracks in heterogeneous layers. Problem is to determine the patterns of change of the opening of crack and the intensity factors of fracture stress at the circles $r=a_{j}$ depending both on the physical and mechanical as well as geometric characteristics of the heterogeneous layers. It is obvious, with such a formulation of the problem, all the middle planes $Z=(2 n+1) h \quad(n \in Z)$ of heterogeneous layers are planes of symmetry, which allows us to separate the base cell as a two-component layer occupying a region $\Omega\{|z| \leq h ; 0 \leq r<\infty ; 0 \leq \varphi \leq 2 \pi\}$ in space and state the problem as a boundary value problem for this layer. Fig.1 shows the axial section of the base cell.

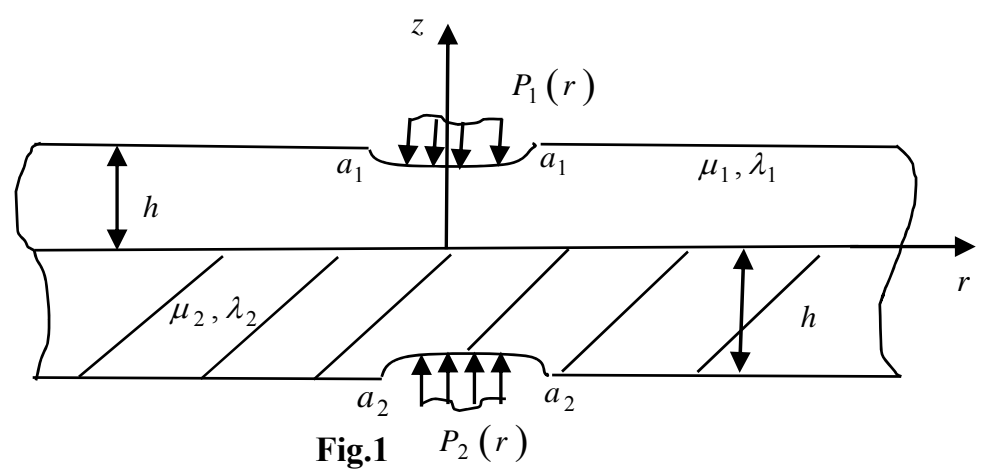


Using indices 1 and 2 for all the parameters describing the stress state of the heterogeneous layers of the base cell, respectively, we write the problem as the following boundary value:

$$
\begin{aligned}
& \left\{\begin{array}{ll}
\tau_{r z}^{(j)}\left(r,(-1)^{j+1} h\right)=0 & (0 \leq r<\infty) \\
u_{z}^{(j)}\left(r,(-1)^{j+1} h\right)=0 & \left(a_{j} \leq r<\infty\right) \\
\sigma_{z}^{(j)}(r, h)=-P_{j}(r) & \left(0 \leq r<a_{j}\right)
\end{array} \quad(j=1,2)\right. \\
& \begin{cases}u_{r}^{(1)}(r, 0)=u_{r}^{(2)}(r, 0) & (0 \leq r<\infty) \\
u_{z}^{(1)}(r, 0)=u_{z}^{(2)}(r, 0) & (0 \leq r<\infty) \\
\sigma_{z}^{(1)}(r, 0)=\sigma_{z}^{(2)}(r, 0) & (0 \leq r<\infty) \\
\tau_{r z}^{(1)}(r, 0)=\tau_{r z}^{(2)}(r, 0) & (0 \leq r<\infty)\end{cases}
\end{aligned}
$$

Here $u_{r}^{(j)}(r, z)$ and $u_{z}^{(j)}(r, z)(j=1,2)$ are respectively the radial and vertical displacements of the points of the layers, and $\sigma_{z}^{(j)}(r, z)$ and $\tau_{r z}^{(j)}(r, z)$ are the normal and radial stresses acting in the corresponding layers. To construct a solution to the boundary value problem (1.1), we represent the solutions of the Lame equations in the form of Hankel integrals [1]:

$$
\begin{aligned}
& u_{r}^{(j)}(r, z)=\int_{0}^{\infty}\left[\left(A_{j}(s)+z B_{j}^{*}(s)\right) \operatorname{ch}(z s)+\left(B_{j}(s)+z A_{j}^{*}(s)\right) \operatorname{sh}(z s)\right] s J_{1}(r s) d s ; \\
& u_{z}^{(j)}(r, z)=\int_{0}^{\infty}\left[\left(C_{j}(s)-z A_{j}^{*}(s)\right) \operatorname{ch}(z s)+\left(D_{j}(s)-z B_{j}^{*}(s)\right) \operatorname{sh}(z s)\right] s J_{0}(r s) d s, \\
& A_{j}^{*}(s)=\frac{s}{\mathfrak{x}_{j}}\left(A_{j}(s)+D_{j}(s)\right) ; B_{j}^{*}(s)=\frac{s}{\mathfrak{x}_{j}}\left(B_{j}(s)+C_{j}(s)\right)(j=1,2),
\end{aligned}
$$

$J_{j}(x)(j=0,1)$ - the Bessel functions of the real argument, $A_{j}(s), B_{j}(s), C_{j}(s)$, $D_{j}(s)$ are the unknown coefficients to be determined, and $\mathfrak{x}_{j}(j=1,2)$ the known constants of Muskhelishvili. To solve the boundary value problem (1.1), we introduce into consideration the unknown functions of the displacements of the crack edges.

$u_{z}\left(r,(-1)^{j+1} h\right)=\frac{(-1)^{j}}{2} w_{j}(r)\left(0<r<a_{j}\right)$,

and solve an auxiliary boundary-value problem consisting of conditions (1.1), in which the last conditions (1.1a) are replaced by conditions (1.3). Then, using Hooke's law and 
representations (1.2), we determine the stress components, satisfy the conditions of the auxiliary boundary value problem, and determine the unknown coefficients $A_{j}(s), B_{j}(s), C_{j}(s), D_{j}(s)$ through Hankel trasponants of the functions of the displacements of the crack edges. The following is obtained

$$
\begin{aligned}
& A_{1}^{*}(s)=-\frac{\left[\mu_{2} \mathfrak{}_{1} \vartheta_{2}^{(1)}-\mu_{1}\left(\mu_{1}-\mu_{2}\right) \beta \operatorname{th} \beta\right]}{2 \mathfrak{x}_{1} \vartheta_{2}^{(1)} \Delta_{1}(\beta) \operatorname{ch} \beta} \mathrm{s} \bar{w}_{1}(s)-\frac{\mu_{2} s \bar{w}_{2}(s)}{2 \Delta_{1}(\beta) \operatorname{ch} \beta} ; \\
& A_{2}^{*}(s)=-\frac{\mu_{1} s \bar{w}_{1}(s)}{2 \Delta_{2}(\beta) \operatorname{ch} \beta}-\frac{\left[\mu_{1} \mathfrak{x}_{2} \vartheta_{2}^{(2)}+\mu_{1}\left(\mu_{1}-\mu_{2}\right) \beta \operatorname{th} \beta\right]}{2 \mathfrak{x}_{2} \vartheta_{2}^{(2)} \Delta_{2}(\beta) \operatorname{ch} \beta} \mathrm{s} \bar{w}_{2}(s) ; \\
& A_{1}(s)=A_{2}(s)=\frac{1}{\mu_{1}-\mu_{2}}\left[\frac{\mathfrak{x}_{1} \vartheta_{2}^{(1)}}{s} A_{1}^{*}(s)-\frac{\mathfrak{x}_{2} \vartheta_{2}^{(2)}}{s} A_{2}^{*}(s)\right] ; \\
& C_{1}(s)=C_{2}(s)=-\frac{1}{\mu_{1}-\mu_{2}}\left[\operatorname{th} \beta\left(\frac{\mathfrak{x}_{1} \vartheta_{2}^{(1)}}{s} A_{1}^{*}(s)+\frac{\mathfrak{x}_{2} \vartheta_{2}^{(2)}}{s} A_{2}^{*}(s)\right)+\frac{\mu_{1} \bar{w}_{1}(s)}{2 \operatorname{ch} \beta}+\frac{\mu_{2} \bar{w}_{2}(s)}{2 \operatorname{ch} \beta}\right] \\
& B_{1}^{*}(s)=-A_{1}^{*}(s) \operatorname{th} \beta-\frac{\mu_{1} s \bar{w}_{1}(s)}{2 \mathfrak{x}_{1} \vartheta_{2}^{(1)} \operatorname{ch} \beta} ; B_{1}^{*}(s)=A_{2}^{*}(s) \operatorname{th} \beta+\frac{\mu_{2} s \bar{w}_{2}(s)}{2 \mathfrak{x}_{2} \vartheta_{2}^{(2)} \operatorname{ch} \beta} ; \\
& \mathrm{B}_{j}(s)=-C_{j}(s)+\frac{\mathfrak{x}_{j}}{s} B_{j}^{*}(s) ; \quad D_{j}(s)=-A_{j}(s)+\frac{\mathfrak{x}_{j}}{s} A_{j}^{*}(s) ;
\end{aligned}
$$

Here we use the notation:

$$
\begin{aligned}
& \Delta_{j}(\beta)=2 \mathfrak{æ}_{j} \vartheta_{2}^{(j)} \Delta_{j}^{*}(\beta) ; \Delta_{j}^{*}(\beta)=\operatorname{th} \beta+(-1)^{j}\left(\mu_{1}-\mu_{2}\right) E_{j}(\beta) ; \\
& E_{j}(\beta)=\frac{1}{2 \vartheta_{2}^{(j)}}\left[\operatorname{th} \beta-\frac{\beta}{\mathfrak{\mho}_{j} \operatorname{ch}^{2} \beta}\right] ; \quad \bar{w}_{j}(s, z)=\int_{0}^{a_{j}} r w_{j}(r) J_{0}(s r) d r ; \\
& \vartheta_{1}^{(j)}=\frac{\mu_{j}^{2}}{\lambda_{j}+3 \mu_{j}} ; \vartheta_{2}^{(j)}=\frac{\mu_{j}\left(\lambda_{j}+2 \mu_{j}\right)}{\lambda_{j}+3 \mu_{j}} ;(\beta=h s ; j=1,2) .
\end{aligned}
$$

Further, using the obtained values of the coefficients, we determine the normal stresses acting on the cracks through the unknown dislocation functions $w_{j}^{\prime}(r)(j=1,2)$. The following is found:

$$
\begin{aligned}
& \sigma_{z}^{(j)}\left(r,(-1)^{j+1} h\right)=-\vartheta_{j} L_{0,0}^{(2)}\left[w_{j}\right]-L_{0,0}^{(2, j, 1)}\left[w_{1}\right]+L_{0,0}^{(2, j, 2)}\left[w_{2}\right] \quad(j=1,2), \\
& L_{00}^{(2)}\left[w_{j}\right]=\int_{0}^{a_{j}} W_{00}^{(2)}(r, \xi) \xi w_{j}(\xi) d \xi ; \quad W_{m, n}^{(k)}(r, \xi)=\int_{0}^{\infty} t^{k} J_{m}(t r) J_{n}(t \xi) d t
\end{aligned}
$$




$$
\begin{aligned}
& W_{m, n}^{(k, i, j)}(r, \xi)=\int_{0}^{\infty} K_{i, j}(\text { th }) t^{k} J_{m}(t r) J_{n}(t \xi) d t \\
& L_{m, n}^{(k, i, j)}\left[w_{j}\right]=\int_{0}^{\infty} s^{2} K_{i, j}(\mathrm{sh}) \bar{w}_{j}(s) J_{0}(s r) d s=\int_{0}^{a_{j}} W_{m, n}^{(k, i, j)}(r, \xi) \xi w_{j}(\xi) d \xi ; \\
& K_{1,1}(\beta)=\frac{\mu_{1} \operatorname{th} \beta\left[\left(\mu_{1}\left(æ_{1}+1\right)+æ_{1} \mu_{2}\right) \operatorname{sh}^{2} \beta+\left(æ_{1}+1\right)\left(\mu_{1}+\mu_{2}\right) / 2\right]}{\mu_{1}\left(æ_{1}+1\right) \Delta_{1}^{*}(\beta) \Delta_{2}^{*}(\beta) \operatorname{ch}^{2}(\beta)}+ \\
& +\frac{Q_{1,1}(\beta)}{\mu_{1}\left(æ_{1}+1\right) \Delta_{1}^{*}(\beta) \Delta_{2}^{*}(\beta) \operatorname{ch}^{2}(\beta)}-\frac{\mu_{1}}{\vartheta_{2}^{(1)}}\left[\vartheta_{1}^{(1)} \operatorname{th} \beta+\frac{\mu_{1} \beta}{æ_{1}}\right]+ \\
& +\frac{2 \beta \operatorname{th} \beta\left[\left(\mu_{1}+æ_{1} \mu_{2}\right) \operatorname{sh}^{2} \beta+\mu_{2}\left(æ_{1}+1\right) / 2\right]}{\left(æ_{1}+1\right)^{2} \Delta_{1}^{*}(\beta) \operatorname{ch}^{2}(\beta)}-\frac{\mu_{1}}{2\left(1-v_{1}\right)} ; \\
& K_{1,2}(\beta)=-\frac{\mu_{1} \operatorname{th} \beta\left[\mathfrak{x}_{1} \mu_{2} \operatorname{sh}^{2} \beta+\left(æ_{1}+1\right)\left(\mu_{1}+\mu_{2}\right) / 2\right]-Q_{1,2}(\beta)}{\mu_{1}\left(æ_{1}+1\right) \Delta_{1}^{*}(\beta) \Delta_{2}^{*}(\beta) \operatorname{ch}^{2}(\beta)}- \\
& -\frac{\mu_{1} \beta \operatorname{th} \beta}{\left(æ_{2}+1\right) \Delta_{2}^{*}(\beta) \operatorname{ch}^{2}(\beta)} \\
& K_{2,1}(\beta)=\frac{\mu_{2} \operatorname{th} \beta\left[æ_{2} \mu_{1} \operatorname{sh}^{2} \beta+\left(æ_{2}+1\right)\left(\mu_{1}+\mu_{2}\right) / 2\right]+Q_{2,1}(\beta)}{\mu_{2}\left(æ_{2}+1\right) \Delta_{1}^{*}(\beta) \Delta_{2}^{*}(\beta) \operatorname{ch}^{2}(\beta)}+ \\
& +\frac{\mu_{2} \beta \operatorname{th} \beta}{\left(æ_{1}+1\right) \Delta_{1}^{*}(\beta) \operatorname{ch}^{2}(\beta)} \\
& K_{2,2}(\beta)=-\frac{\mu_{2} \operatorname{th} \beta\left[\left(\mu_{2}\left(\mathfrak{x}_{2}+1\right)+\mathfrak{x}_{2} \mu_{1}\right) \operatorname{sh}^{2} \beta+\left(\mathfrak{x}_{2}+1\right)\left(\mu_{1}+\mu_{2}\right) / 2\right]}{\mu_{2}\left(\mathfrak{x}_{2}+1\right) \Delta_{1}^{*}(\beta) \Delta_{2}^{*}(\beta) \operatorname{ch}^{2}(\beta)}+ \\
& +\frac{Q_{2,2}(\beta)}{\mu_{2}\left(æ_{2}+1\right) \Delta_{1}^{*}(\beta) \Delta_{2}^{*}(\beta) \operatorname{ch}^{2}(\beta)}+\frac{\mu_{2}}{\vartheta_{2}^{(2)}}\left[\vartheta_{1}^{(2)} \operatorname{th} \beta+\frac{\mu_{2} \beta}{\mathfrak{x}_{2}}\right]- \\
& -\frac{2 \beta \operatorname{th} \beta\left[\left(\mu_{2}+\mathfrak{x}_{2} \mu_{1}\right) \operatorname{sh}^{2} \beta+\mu_{1}\left(æ_{2}+1\right) / 2\right]}{\left(æ_{2}+1\right)^{2} \Delta_{2}^{*}(\beta) \operatorname{ch}^{2}(\beta)}-\frac{\mu_{2}}{2\left(1-v_{2}\right)} \text {; } \\
& Q_{1,1}(\beta)=-\mu_{1} \mu_{2} E_{2}\left[\left(\mu_{1}+æ_{1} \mu_{2}\right) \operatorname{sh}^{2} \beta+\frac{\mu_{2}\left(æ_{1}+1\right)}{2}\right]-\frac{\mu_{1}^{3}\left(æ_{1}+1\right) E_{1}}{2}+ \\
& +\mu_{1}^{3}\left(æ_{1}+1\right) \operatorname{sh}^{2} \beta\left[E_{2}-E_{1}-\left(\mu_{1}-\mu_{2}\right) E_{1} E_{2} \operatorname{cth} \beta\right]
\end{aligned}
$$




$$
\begin{aligned}
& Q_{1,2}(\beta)=\mu_{1} \mu_{2} E_{2}\left[\left(\mu_{1}+æ_{1} \mu_{2}\right) \operatorname{sh}^{2} \beta+\frac{\mu_{2}\left(æ_{1}+1\right)}{2}\right]+\frac{\mu_{1}^{3}\left(æ_{1}+1\right) E_{1}}{2}- \\
&-\mu_{1}^{2} \mu_{2}\left(æ_{1}+1\right) \operatorname{sh}^{2} \beta\left[E_{2}-E_{1}-\left(\mu_{1}-\mu_{2}\right) E_{1} E_{2} \operatorname{cth} \beta\right] ; \\
& Q_{2,1}(\beta)=-\mu_{1} \mu_{2} E_{1}\left[\left(\mu_{2}+æ_{2} \mu_{1}\right) \operatorname{sh}^{2} \beta+\frac{\mu_{1}\left(æ_{2}+1\right)}{2}\right]-\frac{\mu_{2}^{3}\left(æ_{2}+1\right) E_{2}}{2}- \\
&-\mu_{1} \mu_{2}^{2}\left(æ_{2}+1\right) \operatorname{sh}^{2} \beta\left[E_{2}-E_{1}-\left(\mu_{1}-\mu_{2}\right) E_{1} E_{2} \operatorname{cth} \beta\right] ; \\
& Q_{2,2}(\beta)=\mu_{1} \mu_{2} E_{1}\left[\left(\mu_{2}+\mathfrak{x}_{2} \mu_{1}\right) \operatorname{sh}^{2} \beta+\frac{\mu_{1}\left(æ_{2}+1\right)}{2}\right]+\frac{\mu_{2}^{3}\left(æ_{2}+1\right) E_{2}}{2}+ \\
&+\mu_{2}^{3}\left(æ_{2}+1\right) \operatorname{sh}^{2} \beta\left[E_{2}-E_{1}-\left(\mu_{1}-\mu_{2}\right) E_{1} E_{2} \operatorname{cth} \beta\right] ;\left(\vartheta_{j}=\frac{\mu_{j}}{2\left(1-v_{j}\right)}\right)
\end{aligned}
$$

Note that kernels $W_{m, n}^{(k, i, j)}(r, \xi)$ are regular functions of both arguments. Now we satisfy the last two conditions (1.1a). As a result, to determine the displacements of the points of the edges of cracks, we obtain the following governing system of integral equations:

$-\vartheta_{j} L_{0,0}^{(2)}\left[w_{j}\right]-L_{0,0}^{(2, \mathrm{j}, 1)}\left[w_{1}\right]+L_{0,0}^{(2, \mathrm{j}, 2)}\left[w_{2}\right]=-P_{j}(r)\left(0<r<a_{j}, \quad j=1,2\right)$,

which should be considered taking into account the conditions of continuity of displacements on circles $r=a_{j}$

$w_{j}\left(a_{j}\right)=0(j=1,2)$

\section{The solution of the governing system of integral equations}

To solve the system of integral equations (1.5), using the rotation operator

$I[\varphi(r)]=\int_{0}^{x} \frac{r \varphi(r) d r}{\sqrt{x^{2}-r^{2}}}$

we reduce it to a system of Fredholm integral equations of the second kind. In this order, as in [2], we introduce functions

$V_{j}(t)=\frac{2}{\pi} \int_{t}^{a_{j}} \frac{\xi w_{j}(\xi) d \xi}{\sqrt{\xi^{2}-t^{2}}}(j=1,2)$

continue them on the interval $\left(-a_{j}, 0\right)$ as an even function and, taking into account the relations,

$$
\begin{aligned}
& \bar{w}_{j}(s)=\frac{2}{\pi} \int_{0}^{a_{j}}\left[\int_{t}^{a_{j}} \frac{r w_{j}(r) d r}{\sqrt{r^{2}-t^{2}}}\right] \cos (t s) d t=\int_{0}^{a_{j}} V_{j}(t) \cos (t s) d t \\
& L_{0,0}^{(2)}\left[w_{j}\right]=\int_{0}^{a_{j}} V_{j}(t) d t \int_{0}^{\infty} s^{2} J_{0}(s r) \cos (t s) d s=-\int_{0}^{a_{j}} V_{j}^{\prime}(t) d t \int_{0}^{\infty} s J_{0}(s r) \sin (t s) d s ;
\end{aligned}
$$


$L_{0,0}^{(2, i, j)}\left[w_{j}\right]=-\int_{0}^{a_{j}} V_{j}^{\prime}(t) d t \int_{0}^{\infty} K_{i, j}(s) s J_{0}(s r) \sin (t s) d s$,

rewrite the system (1.5) in the following form:

$\vartheta_{j} \int_{0}^{a_{j}} R(t, r) V_{j}^{\prime}(t) d t+\sum_{i=1}^{2} \int_{0}^{a_{i}} R_{j, i}(t, r) V_{i}^{\prime}(t) d t=-P_{j}(r) ;$

$$
\left(0<r<a_{j}, \quad j=1,2\right),
$$

$R(r, t)=\int_{0}^{\infty} s J_{0}(s r) \sin s t d s ; \quad R_{j, i}(r, t)=(-1)^{i+1} \int_{0}^{\infty} K_{j, i}(s) s J_{0}(s r) \sin s t d s$.

From representation (2.1) it appears that $V_{j}\left(a_{j}\right)=0$. In this case, the conditions (1.6) are satisfied automatically, since using the inverse operators of rotation operators [1-3], functions can be written in the following form

$w_{j}(r)=-\frac{1}{r} \frac{d}{d r} \int_{r}^{a_{j}} \frac{s V_{j}(s)}{\sqrt{s^{2}-r^{2}}} d s=-\int_{r}^{a_{j}} \frac{V_{j}^{\prime}(s)}{\sqrt{s^{2}-r^{2}}} d s \quad(j=1,2)$

Further, we apply the operator $I$ to both parts of equations (2.2). After calculations, using the values of known integrals

$\int_{0}^{x} \frac{J_{0}(r t) r d r}{\sqrt{x^{2}-r^{2}}}=\frac{\sin (x t)}{t} ; \int_{0}^{\infty} \sin (s t) \sin (s x) d s=\frac{\pi}{2}[\delta(t-x)-\delta(t+x)]$,

where $\delta(x)$ is the well-known Dirac function, we come to the following system of integral equations of the second kind of Fredholm type:

$V_{j}^{\prime}(x)+\sum_{i=1}^{2} \int_{-a_{j}}^{a_{j}} R_{j, i}^{*}(t, x) V_{i}^{\prime}(t) d t=f_{j}(x) \quad(j=1,2) ;$

$f_{j}(x)=-\frac{2}{\pi \vartheta_{j}} I\left[P_{j}(r)\right]$

$R_{j, i}^{*}(t, x)=\frac{(-1)^{i+1}}{\pi \vartheta_{j}} \int_{0}^{\infty} K_{j, i}(s) \sin (t s) \sin (x s) d s . \quad(i, j=1,2)$

With the help of the replacements of variables $t=a_{j} \xi, x=a_{j} \eta(j=1,2)$, we formulate the obtained equations on the interval $(-1,1)$ and denote $\varphi_{j}(\eta)=V_{j}^{\prime}\left(a_{j} \eta\right) / a_{j}$ we come to the system

$\varphi_{j}(\eta)+\sum_{i=1}^{2} \int_{-1}^{1} Q_{j, i}^{*}(\xi, \eta) \varphi_{i}(\xi) d \xi=f_{j}^{*}(\eta) \quad(-1<\eta<1, j=1,2)$, 
$Q_{1,1}^{*}(\xi, \eta)=l_{1} R_{1,1}^{*}\left(l_{1} \xi, l_{1} \eta\right) ; Q_{2,2}^{*}(\xi, \eta)=l_{2} R_{2,2}^{*}\left(l_{2} \xi, 1_{2} \eta\right)$

$Q_{1,2}^{*}(\xi, \eta)=\frac{l_{2}^{2}}{l_{1}} R_{1,2}^{*}\left(l_{2} \xi, l_{1} \eta\right) ; Q_{2,1}^{*}(\xi, \eta)=\frac{l_{1}^{2}}{l_{2}} R_{2,1}^{*}\left(l_{1} \xi, l_{2} \eta\right) ;$

$f_{j}^{*}(\eta)=-I\left[P_{j}\left(a_{j} \xi\right)\right] / \mathrm{a}_{j} ; \quad\left(l_{j}=a_{j} / h ; j=1,2\right)$.

Thus, the solution of the problem was reduced to solving a system of integral equations of the second kind of Fredholm type (2.5), the solution of which can be constructed by the method of successive approximations. It is obvious that the solutions of this system functions $\varphi_{j}(x)(j=1,2)$ are bounded on circles $r=a_{j}$, respectively. We will also write formulas with the help of which, after determining the functions $\varphi_{j}(\eta)$, it is possible to find the crack opening and the intensity factors of fracture stresses on the circles $r=a_{j}$. To determine the crack opening, we use formulas (2.3), from where we get the formulas for dimensionless crack openings:

$W_{j}^{*}(\eta)=\frac{w_{j}\left(a_{j} \eta\right)}{a_{j}}=-\int_{\eta}^{1} \frac{\varphi_{j}(\xi)}{\sqrt{\xi^{2}-\eta^{2}}} d \xi$.

To determine the intensity factors of fracture stresses $K_{I}^{(j)}\left(a_{j}\right)$ on the circles $r=a_{j}(j=1,2)$ the formulas (1.7) with $(r>a)$ are represented in the form:

$\sigma_{z}^{(j)}\left(r,(-1)^{j+1} h\right)=\vartheta_{j} \int_{0}^{a_{j}} R(t, r) V_{j}^{\prime}(t) d t+\sum_{i=1}^{2} \int_{0}^{a_{i}} R_{j, i}(t, r) V_{i}^{\prime}(t) d t$

Further, using known formulas [5]

$s J_{0}(r s)=\frac{1}{r} \frac{d}{d r}\left(r J_{1}(r s)\right) ; \quad \int_{0}^{\infty} J_{1}(s r) \sin t s d s=\left\{\begin{array}{ll}0 & t>r \\ \frac{t}{r} \frac{1}{\sqrt{r^{2}-t^{2}}} & t<r\end{array}\right.$,

(2.7) we write in the following form

$$
\begin{aligned}
& \sigma_{z}^{(j)}\left(r,(-1)^{j+1} h\right)=\frac{\vartheta_{j}}{r} \frac{d}{d r} \int_{0}^{a_{j}} \frac{t V_{j}^{\prime}(t) d t}{\sqrt{r^{2}-t^{2}}}+\sum_{i=1}^{2} \int_{0}^{a_{i}} R_{j, i}(t, r) V_{i}^{\prime}(t) d t= \\
& =-\frac{\vartheta_{j} V_{j}^{\prime}\left(a_{j}\right)}{\sqrt{r^{2}-a_{j}^{2}}}+F_{j}(r) . \\
& F_{j}(r)=\sum_{i=1}^{2} \int_{0}^{a_{i}} R_{j, i}(t, r) V_{i}^{\prime}(t) d t+\frac{\vartheta_{j}}{r} \frac{d}{d r} \int_{0}^{a_{j}} \frac{t\left[V_{j}^{\prime}(t)-V_{j}^{\prime}\left(a_{j}\right)\right] d t}{\sqrt{r^{2}-t^{2}}}+\vartheta_{j} V_{j}^{\prime}\left(a_{j}\right) / r
\end{aligned}
$$

bounded functions respectively on circles $r=a_{j}(j=1,2)$. From (2.8) we find 


$$
\begin{aligned}
K_{I}^{(j)}\left(a_{j}\right) & =\lim _{r \rightarrow a+0} \sqrt{2\left(r-a_{j}\right)} \sigma_{z}^{(j)}\left(r,(-1)^{j+1} h\right)=-\vartheta_{j} V_{j}^{\prime}\left(a_{j}\right) / \sqrt{a_{j}}= \\
& =-\sqrt{a} \vartheta_{j} \varphi_{j}(1)(j=1,2) .
\end{aligned}
$$

Consequently, the dimensionless intensity factors of fracture stresses on circles $r=a_{j}(j=1,2)$ can be determined by the formulas:

$$
K_{I, \mathrm{j}}^{*}(a)=K_{I}^{(j)}\left(a_{j}\right) / \sqrt{a_{j}} \mu_{1}=-\left(\frac{\mu_{j}}{\mu_{1}}\right) \frac{\varphi_{j}(1)}{2\left(1-v_{j}\right)} .
$$

\section{Numerical analysis}

Using the method of mechanical quadrature, the numerical analysis is carried out and the regulations of change of dimensionless intensity coefficients of fracture stresses $K_{I, \mathrm{j}}^{*}\left(a_{j}\right)$ and dimensionless crack opening $W_{j}^{*}(x)=w_{j}\left(a_{j} x\right) / a_{j}$ depending on the parameter $l_{j}=a_{j} / h$ change in the case where $a_{1}=a_{2}=a, l_{1}=l_{2}=l, P_{j}(r)=P_{0}=$ const, $P_{1}^{*}=P_{0} / \mu_{1}=0.1, P_{2}^{*}=P_{0} / \mu_{2}=0.2, v_{1}=0,25, \quad v_{2}=0,3 \quad(j=1,2)$. At the same time, the right parts of system (2.5) have the following form:

$f_{j}^{*}(\eta)=-\frac{4\left(1-v_{j}\right)}{\pi} P_{j}^{*} \eta \quad(j=1,2)$.

The results of numerical calculations are shown in Table 1 and in Fig. 2a and 2b. Table 1 shows the values of the dimensionless intensity factors $K_{I, j}^{*}(a)(j=1,2)$ depending on the parameter $l=a / h$. The calculations show that with a decrease of $l$, which can be interpreted as an increase in the height $h$ of the layers, with a constant $a$, the intensity factors increase, tending to a certain limit, corresponding to the case of a homogeneous space, made respectively of the first and second materials with one disk-shaped crack. Figures $2 \mathrm{a}$ and $2 \mathrm{~b}$ show the graphs of crack opening depending on the parameter $l$.

Table 1. Intensity Factors depending on $l$

\begin{tabular}{|c|l|l|l|l|c|c|}
\hline$l$ & 0.1 & 0.2 & 0.5 & 1 & 2 & 10 \\
\hline$K_{I, 1}^{*}(a)$ & 0.06662 & 0.06649 & 0.06543 & 0.06197 & 0.05459 & 0.03327 \\
\hline$K_{I, 2}^{*}(a)$ & 0.07138 & 0.07121 & 0.06981 & 0.06566 & 0.05833 & 0.03832 \\
\hline
\end{tabular}

It can be seen from Figures that when $l$ is decreasing, i.e. when removing cracks, the openings of crack also increases, tending to a certain limit, corresponding to the opening of one disk-shaped crack in a homogeneous space, made respectively of the material of the first and second layers. 


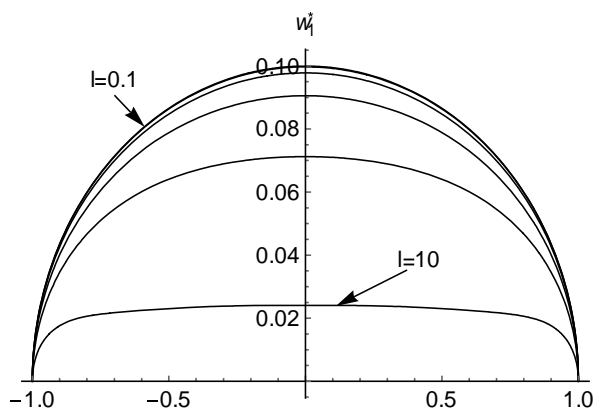

Fig. 2a. The first crack openings

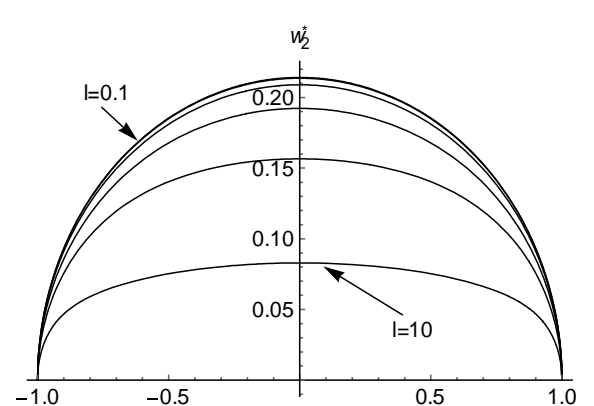

Fig. 2b. The second crack openings

Table 2 and Fig. 3a and $3 \mathrm{~b}$ show the values of the dimensionless intensity factors $K_{I, j}^{*}(a)(j=1,2)$ and the graphs of crack openings $W_{j}^{*}(x)$ as a function of the parameter $\mu=\mu_{2} / \mu_{1}$ in the case when $l=2, v_{1}=0,4, v_{2}=0,25 P_{1}^{*}=0.1$.

Table 2. Intensity factors depending on $\mu$

$\begin{array}{ccccccc}\mu & 1 & 2 & 5 & 10 & 50 & 100 \\ K_{I, 1}^{*}(a) & 0.0707 & 0.0662 & 0.0608 & 0.0578 & 0.0544 & 0.0538 \\ K_{I, 2}^{*}(a) & 0.0377 & 0.0349 & 0.0311 & 0.0289 & 0.0261 & 0.0257\end{array}$

The Tables show that in the this case, with an increase of $\mu$, which can be interpreted as an increase of $\mu_{2}$, with a constant $\mu_{1}$, as the intensity factors of the fracture stress on the bounding circles of both cracks, and the opening of crack decrease.

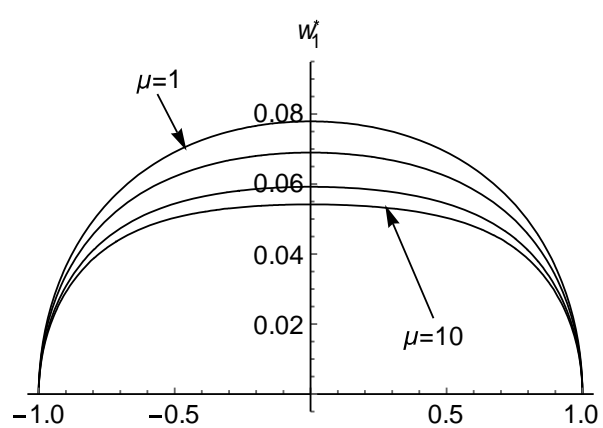

Fig. 3a. The first crack opening

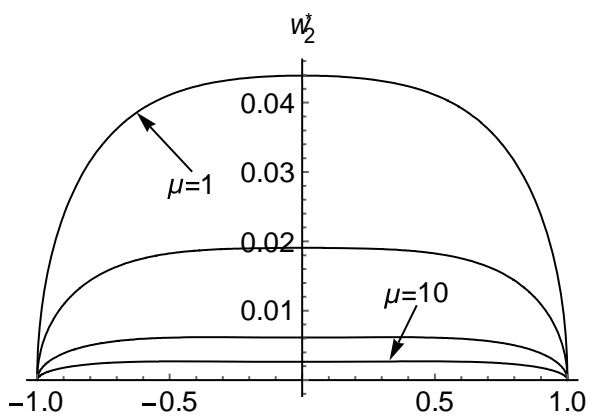

Fig. 3b. The second crack opening 


\section{CONCLUSION}

Thus, a governing system of integral equations for a piecewise homogeneous, uniformly layered space with periodic systems of circular disk-shaped parallel internal cracks is obtained. The solution of system is constructed by the numerical-analytical method of mechanical quadratures. By numerical analysis, it is shown that the mutual influence of cracks increases when they approach each other. In the case of the removal of cracks from each other, they work as separate, single disk-shaped cracks in homogeneous spaces, made respectively of the material of the first and second layers. It is also shown that with an increase of the rigidity of one of the layers, when the rigidity of the other layer does not change, it leads to a decrease in both the intensity factors of the fracture stresses on the bounding circles of both cracks and their opening.

The study was carried out with the financial support of the Committee on Science and Education of the Ministry of Education and Science of the Republic of Armenia and the Russian Foundation for Basic Research (RFBR) within the framework of the joint research project SCS 18RF061 and RFBR 18-51-05012.

\section{REFERENCES}

1. Hakobyan V.N., Hakobyan L.V., Dashtoyan L.L. The discontinuous solutions of axissymmetrical theory of elasticity for piecewise homogeneous, layered space with periodical interphase disk-shaped defects //Mechanics of composite Materials. Vol.55. 2019, pp.2-24.

2. Popov G.Ya. Selected works. Edition VMV. Vol.1, 2007. 440p.

3. Popov G.Ya. Selected works. Edition VMV. Vol.2. 2007. 516p.

4. Hakobyan V.N. Stress concentration near defects in homogeneous and compound bodies. Gitutyun, NAS RA, Yerevan -2014, 322p. Изд-во «Гитутюн НАН РА», Ереван -2014, 322c.

5. Gradshtein I.S., Ryzhik I.M. Tables of integrals, series and products. Moscow: FizMatLit, 1962, 1110p.

\section{Information about the authors:}

Hakobyan V.N. - Institute of Mechanics NAS RA, Yerevan, Armenia, Baghramyan 24/2 ave., 0019 Yerevan, Armenia. E-mail: vhakobyan@sci.am

Dashtoyan L.L. - Institute of Mechanics NAS RA, Yerevan, Armenia, Baghramyan 24/2 ave., 0019 Yerevan, Armenia

Murashkin Ye. V. - Ishlinsky Institute for Problems in Mechanics, of the Russian Academy of Sciences, Pr. Vernadskogo, 101-1, 119526 Moscow, Russia

Received 01.11.2019 